\title{
Artelogie
}

Recherche sur les arts, le patrimoine et la littérature de l'Amérique latine

$14 \mid 2019$

Sensibilités : Arts, littératures et patrimoine en Amérique latine

\section{$O$ arquivo pessoal da historiadora Sandra Jatahy Pesavento e as Sensibilidades enquanto campo teórico e método de análise histórica}

Nádia Maria Weber Santos e Maximiano Martins de Meireles

\author{
(2) OpenEdition \\ Journals \\ Edição electrónica \\ URL: http://journals.openedition.org/artelogie/3933 \\ DOI: 10.4000/artelogie.3933 \\ ISSN: 2115-6395 \\ Editora \\ Association ESCAL \\ Refêrencia eletrónica \\ Nádia Maria Weber Santos e Maximiano Martins de Meireles, « $\mathrm{O}$ arquivo pessoal da historiadora \\ Sandra Jatahy Pesavento e as Sensibilidades enquanto campo teórico e método de análise histórica \\ », Artelogie [Online], 14 | 2019, posto online no dia 07 janeiro 2019, consultado o 17 setembro 2019. \\ URL : http://journals.openedition.org/artelogie/3933 ; DOI : 10.4000/artelogie.3933
}

Este documento foi criado de forma automática no dia 17 Setembro 2019.

Association ESCAL 


\section{$O$ arquivo pessoal da historiadora Sandra Jatahy Pesavento e as Sensibilidades enquanto campo teórico e método de análise histórica}

Nádia Maria Weber Santos e Maximiano Martins de Meireles

\section{Introdução}

1 O texto pretende discutir o lugar, a importância e os conteúdos específicos da temática das Sensibilidades na obra da historiadora Sandra Jatahy Pesavento, a partir dos documentos de seu arquivo pessoal, que está depositado no Instituto Histórico e Geográfico do Rio Grande do Sul (IHGRGS) desde final de 2014, por doação da família. O material completo do Acervo Sandra Jatahy Pesavento (doravante Acervo SJP) tem em torno de 114 metros lineares, abrangendo a biblioteca da historiadora, o material de estudo e de pesquisa dos 40 anos de trabalho da professora e pesquisadora, as obras completas digitalizadas e fichário completo, incluindo fichamento de jornais do RS dos séculos XIX e início do XX.

2 A historiadora Sandra Jatahy Pesavento (1946-2009) - pesquisadora 1A do CNPq (de 1996 até 2009) e professora titular de História da UFRGS (desde 1991) - foi professora titular do Departamento de História da UFRGS e professora dos Programas de Pós-Graduação de História e do PROPUR da mesma instituição. Fez doutorado em História Econômica na USP e possuía 3 pós-doutorados em Paris, rumando neste momento (início da década de 1990) para o campo da História Cultural, de onde foi uma das pioneiras no Brasil. Foi uma das primeiras pesquisadoras $1 \mathrm{~A}$ do CNPq na área de História e tinha interlocução com autores e historiadores de vários países. Autora de uma vasta obra historiográfica, com 126 artigos publicados no Brasil e no exterior, 51 livros, entre individuais e coletivos e 85 
capítulos de livros, é uma das mais importantes historiadoras do século XX, cuja obra versa sobre variadas vertentes da historiografia. Da História Econômica, com viés marxista, à História Cultural, sua riquíssima obra estuda e pesquisa as charqueadas gaúchas, a Revolução Farroupilha, a burguesia gaúcha e a industrialização, e, também, as questões do urbano, das imagens, das sensibilidades e da relação História/Literatura, estas últimas já sob o enfoque da História Cultural.

Por iniciativa da família Pesavento, os escritos da historiadora gaúcha foram digitalizados integralmente e disponibilizados gratuitamente para a comunidade acadêmica e para a sociedade em geral, constando no site do IHGRGS. $O$ acervo intelectual da pesquisadora, constituído durante os 40 anos em que foi atuante como historiadora, bem como sua grande e importante biblioteca de aproximados 4 mil títulos estão depositados no IHGRGS e em fase de organização.

4 A importância de suas pesquisas na História Cultural, em âmbito nacional e internacional, é validada pelos inúmeros trabalhos acadêmicos que citam suas obras. Sua especificidade em lidar com os arquivos e com as fontes históricas é reconhecida, legado este que seus ex-orientandos e interlocutores compartilham e transmitem a seus alunos. Como historiadora da cidade de Porto Alegre e do Rio Grande do Sul, ela era popular e muito solicitada a compartilhar seus conhecimentos históricos com a população em geral e na mídia. Variados campos de estudos têm em sua obra balizadores conceituais. No estudo do Acervo SJP, metodologicamente cruzando suas leituras (livros de sua biblioteca) com os documentos que ela produziu nos quarenta anos de sua atuação como professora e pesquisadora (entre eles, manuscritos de suas obras e de sua produção intelectual, resenhas de autores e livros, projetos de pesquisa, planos de aulas, transcrição de fontes primárias, coleção de imagens, reflexões sobre suas temáticas preferencias - urbano, sensibilidades, imagens, literatura) e com sua produção intelectual (artigos, livros e capítulos, entre outros), é possível não somente traçar a trajetória intelectual da pesquisadora, como trazer à tona a importância de seu pensamento para a historiografia brasileira, desde a década de 1970 .

5 A professora Pesavento foi uma historiadora altamente produtiva, como pesquisadora do $\mathrm{CNPq}$, tendo galgado a posição de pesquisadora $1 \mathrm{~A}$ numa época em que poucos conseguiam, graças à sua produtividade. Desde a fase marxista, pesquisando a economia gaúcha, a industrialização, as Charqueadas, até a fase em que pensou o urbano, os excluídos, as sensibilidades dos homens do passado, ela publicou muito, formou várias gerações de historiadores, influenciou pensamentos, pesquisas, dentro e fora do Brasil. Tudo isto está documentado em seu acervo, arquivo pessoal este que precisa ser estudado com maior profundidade e preservado, pois nele constam documentos importantes de nossa história. Por exemplo, nos 32 arquivos de fichas, há fichamentos de jornais do final do século XIX e início do século XX, dentre eles, A Gazetinha, de 1896 e $O$ Independente, de 1910, de onde retirou fontes para suas pesquisas sobre os Becos e os excluídos da cidade de Porto Alegre, origem de várias de suas produções intelectuais. Alguns periódicos fichados nem existem mais ou estão em má conservação em seus arquivos de origem (como no Museu Hypólito da Costa, de Porto Alegre). Outro exemplo importante são os fichamentos de processos-crime e dos materiais da pesquisa de seu último livro, Os Sete Pecados da Capital, que estão todos arquivados no acervo. Faz-se mister não deixar com que estas fontes históricas se percam em definitivo. Pesavento sabia da importância desta preservação, tanto que organizadamente manteve estas fontes transcritas muito bem 
cuidadas em sua residência, quando viva, e sua família teve a lucidez de enviar ao IHGRGS para custódia.

Dentre esses diversos focos dos conteúdos do Acervo SJP, que perpassam as várias fases da historiadora e pesquisadora da UFRGS (desde os anos de 1970), vamos, no presente artigo, ater-nos aos manuscritos sobre Sensibilidades, os quais abrangem: resumos e resenhas de obras e autores, rascunhos de textos, reflexões originais (manuscritas) sobre Sensibilidades, em português e em francês, entre outros. Sandra Pesavento foi uma das pioneiras na historiografia brasileira do Campo das Sensibilidades, o que demarca a importância de pesquisar em seu arquivo pessoal tal temática e cruzar com os escritos que vieram a público, problematizando e discutindo as possibilidades de investigação no acervo e neste campo temático. Junta-se a isto pensar as sensibilidades enquanto método de investigação da História.

\section{0 arquivo pessoal e intelectual Sandra Jatahy Pesavento no IHGRGS: breve descrição e constituição do acervo}

7 Na presente seção, apresentamos, sucintamente, o arquivo pessoal e intelectual Sandra Jatahy Pesavento (1946-2009) - Acervo SJP - que está depositado no Instituto Histórico e Geográfico do Rio Grande do Sul (IHGRGS) desde final de 2014, por doação da família e, desde lá, passa pelas diversas fases de organização. A referida instituição de custódia se caracteriza como uma instituição privada sem fins lucrativos, fundada a 05 de agosto de 1920, cuja finalidade é promover estudos e investigações sobre História, Geografia, Arqueologia, Filologia, Antropologia e campos correlatos do conhecimento, principalmente centrados no Rio Grande do Sul ${ }^{1}$.

8 Designa-se arquivo pessoal as mais diversas formas de escritas de si e o conjunto dos documentos produzidos e/ou pertencentes a uma pessoa, ou seja, que resulta de uma trajetória profissional, intelectual, social e cultural específica. Considerado como locus de pesquisa, permite ao historiador e demais pesquisadores apreender aspectos micro e macro do social de um dado tempo, sensibilidades de uma pessoa e, por extensão, de um grupo (VIDAL, 2007), contribuindo para o entendimento mais sutil de fenômenos sociológicos e históricos, de ideários políticos, projetos pessoais e processos sociais neles investidos (HEYMANN, 2005).

9 A equipe curatorial do Acervo SJP, constituída em meados de 2015, é responsável pela organização primária do acervo em seus diferentes momentos (triagem, limpeza, classificação - organização nas caixas, pastas, prateleiras e gavetas, descrição e divulgação -, realização de eventos e exposições). 0 material completo do Acervo abrange: I - Coleção Bibliográfica: a biblioteca da historiadora, em torno de 4 mil obras (este material não está catalogado ainda), II - Fundo Documental: o material de estudo e de pesquisa dos 40 anos de trabalho da professora e pesquisadora, compreendendo: II/1 - Pastas suspensas, caixas e gavetões com material de estudo de 40 anos; II/2 - Arquivo digital: obras completas de SJP digitalizadas e II/3 - Arquivo especial de fichas manuscritas: fichário completo, com móvel, pertencente à historiadora, incluindo fichamento de jornais do século XIX e início do século XX do Rio Grande do Sul. O total do acervo físico tem aproximadamente 114 metros lineares de documentação. ${ }^{2}$ 
10 No decorrer deste processo (entre final de 2014 e 2017), a família teve duas iniciativas importantes: a criação de um website sobre a historiadora e a digitalização completa de sua obra (livros individuais e capítulos de livros, perfazendo 121 itens). Com isto, proporcionam uma democratização no compartilhamento público de seus escritos: suas obras digitalizadas estão disponíveis, desde meados de 2017, junto ao website do IHGRGS ${ }^{3}$ e o site sobre ela foi colocado em linha em maio também de 2017 e nele constam: uma linha do tempo da pesquisadora, com imagens selecionadas pela família, incluindo sua vida pessoal e produção das obras, os inéditos carnets de Voyage, escritos em viagem a Paris em 2004, vídeos de entrevistas e fotos, livros individuais publicados e agora digitalizados ${ }^{4}$. Atualmente, todo material documental do acervo físico foi colocado em caixas, gavetas (material de grandes proporções) e pastas suspensas, sendo possível ter uma ideia geral de seu conteúdo e fazer a sua descrição.

11 O processo de organização, constituição e pesquisas já desenvolvidas no Acervo SJP revela a riqueza dos materiais de arquivo e, principalmente, resguarda um percurso de como o campo historiográfico da História Cultural tomou o pensamento e ocupou as reflexões da historiadora gaúcha nos últimos 20 anos de sua vida. Seus estudos sobre o urbano, sobre a relação História e Literatura, sobre imagens e, mais no fim, sobre sensibilidades, estão todos demonstrados nos inúmeros documentos que compõem seu acervo e que intentamos divulgar e propor como fontes para pesquisadores.

$\mathrm{O}$ ato de escrever, por mais antigo que seja, sempre revela. Revela vontades, desejos, maneiras de ser e de se preocupar com o mundo. Revela ideias, reflexões contemporâneas e, muitas vezes, extemporâneas - que podem permear uma vida e uma obra. Não é diferente daquilo que identificamos no Acervo Sandra Jatahy Pesavento. Ou seja, a escrita da historiadora - muitas vezes literalmente manuscrita - revela e expõe muito de seu percurso como pesquisadora, intelectual e professora. Além disto, o material constituinte do acervo revela uma pessoa organizada e interessada em construir um pensamento - que se tornou original em nosso meio acadêmico. Pesavento, ao arquivar sua vida intelectual e pessoal - talvez mesmo sem a intenção consciente de o fazer, como saber? -, deixou para as gerações vindouras a possibilidade de construírem a história de seu pensamento, que foi publicizado por ela em seus livros e artigos. ${ }^{5}$

13 Tal acervo se constitui em um patrimônio histórico que permite o desenvolvimento de pesquisas que se interessem pela trajetória intelectual da historiadora Sandra Jatahy Pesavento (1946-2009), professora titular do Departamento de História da UFRGS e professora dos Programas de Pós-Graduação de História e do PROPUR da mesma instituição. Ele guarda diferentes documentos que tratam da formação acadêmica da referida historiadora, que fez doutorado em História Econômica na USP e possuía 4 pósdoutorados em Paris, bem como de sua trajetória como professora e pesquisadora, demonstrando sua interlocução com autores e historiadores de vários países do mundo.

O Acervo SJP é um campo profícuo de pesquisa para compreender a trajetória desta historiadora, a qual se inscreve em diferentes movimentos e em distintos tempos, revelando as nuances de uma vida dedicada à História, à docência e à pesquisa. Neste sentido, os arquivos que compõem o referido acervo abrem possibilidades para o desenvolvimento de investigações que buscam pensar sobre Sandra Jatahy Pesavento em diferentes campos de atuação: 1) do lugar de intelectual e teórica - suas contribuições na produção do pensamento historiográfico no Brasil e mais especificamente no contexto do Rio Grande do Sul; 2) do lugar de professora - sua carreira docente na Universidade Federal do Rio Grande do Sul UFRGS, no âmbito da graduação e da pós graduação em 
História; 3) do lugar de pesquisadora - as pesquisas desenvolvidas no contexto do Programa de Pós Graduação de História/UFRGS e no âmbito de Pesquisadora de produtividade do CNPq, sua atuação tanto como docente, orientadora, quanto coordenadora; membro da equipe editorial de vários periódicos acadêmicos no Brasil e no exterior; membro de conselho consultivos; membro de associações de historiadores internacionais; membro de Centros de Pesquisas; membro criadora de Grupos de Trabalho (GT de História Cultural na ANPUHRS (1997) e na ANPUH Nacional (2001); coordenadora de Acordos CAPES/COFECUB (França/Brasil).

Todo o material bruto recolhido em sua residência abrange a biblioteca da historiadora, com uma estimativa de quatro mil obras, e o material de pesquisa de quarenta anos, incluindo, entre outros, manuscritos de livros e artigos, transcrição de fontes primárias (processo crime, jornais, prontuários médicos), estudos de autores e temas (fichamentos manuscritos), planos de aulas de graduação e pós-graduação e cursos ministrados, projetos de pesquisa nos vários órgãos de fomento (Capes, CNPq e Fapergs), registros das idas a congressos internacionais, imagens de Porto Alegre coletadas para estudos, correspondências acadêmicas (e-mails impressos), fontes sobre a indústria gaúcha etc.

Como referido acima, a pesquisadora era muito organizada, fazendo com que tenhamos no acervo fardos, pastas e plásticos organizados por ela de assuntos que perfazem toda sua trajetória acadêmica e profissional, como professora da UFRGS e pesquisadora do CNPq. Desde transcrição de fontes primárias (jornais do século XIX, processos crime, relatórios sobre a indústria gaúcha, movimentos de greves de operários, fotos dos sentenciados do álbum do Dr. Sebastião Leão, imagens de Porto Alegre antiga, entre muitas outras), passando por planos de aulas e redações de projetos de pesquisa, anotações sobre arguições de bancas de mestrado e doutorado, correspondências eletrônicas trocadas com editores e colegas companheiros de publicações, manuscritos de palestras proferidas nacional e internacionalmente, o que já denota uma riqueza infindável deste acervo, constatamos que há fichamentos que ela realizava de autores e temas relativos aos seus estudos preliminares de História Cultural e o que seria, mais tarde, conteúdo dos textos de seus livros e artigos.

Temos como exemplificar esta última afirmação com as caixas de número $33 \mathrm{~A}$ e B, que denominamos "Estudos de SJP (Manuscritos) por temas e autores", onde constam 30 envelopes e pastas de plástico, organizadas por ela, com fichamentos de temas e autores importantes para o campo. Na caixa 33 A temos os seguintes autores e temas: Nova História Cultural, Nova História Cultural (origens), Micro História, Imaginário, Representação, Narrativa, Sensibilidades, História e Literatura, Ítalo Calvino, Paul Ricoeur, Carlo Ginzburg, Robert Darnton, Pierre Bourdieu, Antropologia, Grupo sensibilidades, Walter Benjamin, Michel Foucault, Mulheres, estudos de autores e obras. Na caixa 33 B temos: Estado da arte sobre História Cultural no Brasil, Cidade e Literatura, Memória, Identidade, Literatura e História, Edward Thompson, The Lady of Shalott, Eduardo Colombo, Pasta Fronteiras Culturais Cone Sul, Banca Tese Nádia, Materiais variados.

18 Este material documenta, de algum modo, a virada epistemológica que marca a trajetória de Sandra Pesavento ao apostar na História Cultural como uma perspectiva de deslocar seu pensamento historiográfico e se debruçar sobre outros objetos de estudo, temas e fontes. Nos rastros da vasta produção de Pesavento, vê-se uma pesquisadora com olhar aguçado e refinado para temáticas como cotidiano, imaginário, literatura, exclusão, subjetividades, histórias de vidas, e sua estreita relação com o Campo das Sensibilidades. 


\section{0 acervo SJP e suas relações com o Campo das Sensibilidades}

\subsection{A produção teórica sobre sensibilidades na trajetória de Sandra Jatahy Pesavento}

19 Na senda da História das Sensibilidades, que foi um dos últimos campos de pesquisa da historiadora e do qual ela foi uma das pioneiras no Brasil, há registros diretos e indiretos nas várias partes do acervo, configurando-se ao mesmo tempo um grande desafio para estabelecer parâmetros - tanto qualitativos quanto cronológicos - deste campo da ciência e uma grande riqueza no que tange às fontes deixadas por ela. Neste texto oferecemos ao leitor um pouco do que nos é permitido pensar e escrever diante de tal acervo, cuja constituição preserva a memória de um percurso pessoal e intelectual, constituindo-se um patrimônio histórico e de pesquisa.

O Acervo SJP, mais especificamente a caixa 33A, constitui-se em um rico material para entender "desde dentro" como Sandra Pesavento vai tecendo seu pensamento e produção no Campo das Sensibilidades, estabelecendo diferentes diálogos com áreas do saber, com instituições e pesquisadores, pois ali constam cópias de e-mails emitidos e recebidos; diversos manuscritos, a exemplo de uma gama de fichamentos de leitura produzidos por ela. Revela uma pesquisadora que busca formar seu pensamento historiográfico de modo interdisciplinar, através de um dedicado trabalho de leitura, interpretação, síntese e correlação das ideias de autores de distintos campos do conhecimento, a exemplo de Walter Benjamin, Roland Barthes, Roger Chartier, Paul Ricoeur, Frédéric Laupies, Carl Gustav Jung, só para citar alguns. Além disso, a caixa 33A do Acervo SJP abriga textos produzidos para serem apresentados em eventos e que, posteriormente, foram ampliados e publicados em periódicos e capítulos de livros.

Os diversos manuscritos e escritos que compõem a caixa 33A são reveladores do percurso que Sandra Pesavento trilhou para pensar as Sensibilidades como campo da História Cultural, como objeto e também como método. Certamente foi este estudo detalhado, aprofundando e interdisciplinar, este diálogo profícuo com autores de grande relevo intelectual, os diferentes trânsitos e interlocuções acadêmicas, seus investimentos intelectuais, sua articulação com rede de pesquisadores no Brasil e na França, por exemplo, que permitem a historiadora pensar esses diferentes contornos das Sensibilidades no campo da pesquisa em História.

O campo das Sensibilidades, assim, se configura em uma dobra da virada epistemológica que marca a trajetória de Sandra Pesavento ao apostar na História Cultural como uma perspectiva de deslocar seu pensamento historiográfico e se debruçar sobre outros objetos de estudo, temas e fontes. Nos rastros da vasta produção de Pesavento, vê-se uma pesquisadora com olhar aguçado e refinado para temáticas como cotidiano, imaginário, exclusão, subjetividades, histórias de vidas, entre outras. Entretanto, interessa-nos, mais especificamente, nesta parte do texto, abordar sobre seus estudos e pesquisas no âmbito das Sensibilidades, temática muito pertinente aos atuais estudos da História Cultural, e tão cara a esta historiadora da cultura. Para tanto, percorremos a trajetória intelectual da historiadora, exemplificando com informações recolhidas em documentos que fazem parte do Acervo SJP, bem como na análise de seu currículo Lattes. 
23 Não é tarefa fácil precisar um marco inicial ou fixar em datas o momento em que as sensibilidades passam a ser um interesse da historiadora, posto que isto tem a ver com posições sensíveis e conscientes que atravessam a vida profissional e intelectual de Pesavento (SANTOS, 2015). Mas certamente é quando ela assume o lugar de historiadora da Cultura, nos vinte últimos anos de sua vida acadêmica, trabalhando com temas ligados à história do urbano, relação entre história e literatura, a relação história/imagem, o mundo dos excluídos, dentre outros, que a história das sensibilidades vai sendo traçada em sua obra, culminando em uma vertente que traduz o fôlego e um dos principais interesses de pesquisa da "última" Sandra Pesavento.

Se já na década de 1990 Pesavento, ao tratar de temas vinculados à História Cultural, deixa entrever nuances das sensibilidades em suas formas de tematizar, pensar e produzir a história, é entre o final do século XX e o início do século XXI que sua produção intelectual vai se concentrar nesta temática, ou seja, é quando as Sensibilidades tomam posição de relevo em sua obra. É mais precisamente entre os anos de 2000 a 2009, conforme se pode ver em seu currículo Lattes, que a História das Sensibilidades assume um lugar de centralidade em sua produção historiográfica, no desenvolvimento de seus "últimos" projetos de pesquisa, na publicação de livros e capítulos de livros, artigos publicados em periódicos, participação e apresentação de trabalhos em eventos acadêmicos, orientações e supervisões de pesquisas em mestrado e doutorado, organização de eventos, participação em bancas, em reuniões de grupo de pesquisa, além de outras produções bibliográficas e técnicas.

25 A questão das Sensibilidades situa-se em suas produções sob duas vertentes: no entrelace com outros temas da História Cultural, a exemplo do imaginário, imaginário urbano, cidades, imagem, memória, exclusão, violência, identidade nacional, a relação história e literatura etc.; e em trabalhos nos quais as Sensibilidades são tematizadas mais especificamente como lastro teórico ou como método para o historiador. Isto pode ser percebido tanto em seu currículo Lattes quanto nos diversos documentos abrigados no Acervo SJP, sobretudo no material arquivado na caixa $33 \mathrm{~A}$ (Sensibilidades e outros temas, conforme explicitado na seção anterior), elencada acima, nosso interesse de pesquisa no atual momento.

Pode-se assim dizer que a História Cultural e a História das Sensibilidades, em sua diversidade de temas e fontes, com seus diferentes modos de acessar, interpretar e produzir a história, aproxima Sandra da interdisciplinaridade, uma pesquisadora que se articulava e agregava pessoas de várias áreas entre alunos de pós-graduação, companheiros de projetos de pesquisa, eventos e publicações, estabelecendo diálogos profícuos, por exemplo, entre as Sensibilidades e as diversas áreas do saber, e isto é visível e notório em sua obra: arquitetura e urbano, literatura, psicologia, psiquiatria, comunicação, antropologia, direito, artes, entre outras (SANTOS, 2015).

Pensar as Sensibilidades como campo da História, a partir das reflexões de Pesavento (2005), é assumir que os homens, em diferentes tempos e espaços, representam e atribuem sentidos ao mundo, nas formas de sentir, pensar, perceber e expressar a realidade. É entender que a História não se move fora da experiência, das subjetividades, da imaginação, das emoções, das ideias, dos desejos, dos temores, posto que a relação dos homens com o mundo está para além do conhecimento científico, dos "frios da razão". É reconhecer em todas as épocas a permanência dos sentimentos, do sensível, daquilo que não é apreendido unicamente pelo racional. 
28 As sensibilidades são traduções da experiência expressas em ritos, atos, palavras e imagens, objetos da vida material, em materialidades do espaço construído. A autora entende as sensibilidades como uma forma de ser e estar no mundo, um processo subjetivo, que brota do íntimo de cada indivíduo, uma experiência única, mas que não é, a rigor, intransferível, elas podem ser também compartilhadas, uma vez que são sempre sociais e históricas (PESAVENTO, 2005: p. 128).

Esta compreensão abre um leque de fenômenos e de objetos de estudos antes desconsiderados pela história. Desse modo, a partir da formulação de questões e objetivos de pesquisa, da definição de fontes, o historiador pode adentrar o passado e interpretar as sensibilidades enquanto conteúdo, formas e símbolos, em um determinado contexto temático e temporal. Pode-se exemplificar esta questão a partir de temas trabalhados pela própria Sandra Pesavento, e, dentre tantos, citamos apenas dois: a relação entre nação, identidade nacional e sensibilidades no Brasil do Oitocentos (PESAVENTO, 2009); crimes, violências e sensibilidades urbanas no sul brasileiro do final do século XIX (PESAVENTO, 2004).

30 Sandra Pesavento $(2003 ; 2007)$ aborda as Sensibilidades não apenas como campo da história ou um conceito, mas também como um método de investigação da História, especialmente da História Cultural. É um método que permite ao historiador compor uma narrativa do passado quando se dedica a ler as formas de ver, sentir e perceber dos homens de uma outra época, ou seja, as sensibilidades de um outro no tempo: "Toda experiência sensível do mundo, partilhada ou não, que exprima uma subjetividade ou uma sensibilidade partilhada, coletiva, deve se oferecer à leitura enquanto fonte, precisando ser objetivada em um registro que permita a apreensão dos seus significados. O historiador precisa, pois, encontrar a tradução das subjetividades e dos sentimentos em materialidades, objetividades palpáveis, que operem como a manifestação exterior de uma experiência íntima, individual ou coletiva". (PESAVENTO, 2003: p. 132). Mais adiante na próxima seção, veremos um dos manuscritos de seu acervo que remete a estas questões.

31 É através das Sensibilidades como campo, objeto e método que o historiador pode capturar a vida no tempo; trabalhar com experiências individuais e coletivas; reconstruir formas de conhecimento do mundo; conhecer o modo como os homens pensam, sentem e se colocam diante do mundo em um contexto cultural e temporal específico; como apreendem o mundo em que vivem etc.

Estes exemplos enunciam, portanto, que o acervo abriga documentos/fontes de extrema relevância para pesquisadores que se interessem em compreender os percursos e os processos de formação do pensamento da historiadora, a partir de um olhar "de bastidores". Trata-se de lançar mão de diversas formas de escritas de si e um conjunto de documentos produzidos e pertencentes a Pesavento, que tratam de sua trajetória profissional, intelectual, social e cultural. Pesquisar o acervo pessoal e intelectual Sandra Jatahy Pesavento é, portanto, um caminho para pensar possibilidades e desafios teóricos e metodológicos da História Cultural colocando em cena novas questões, temas, objetos de pesquisa e fontes. Tal perspectiva nos encaminha ao horizonte das Sensibilidades enquanto método de análise histórica, percorrendo as proposições de Sandra Pesavento a partir de documentos de seu acervo. 


\subsection{As Sensibilidades enquanto método de análise histórica}

Dentre as inúmeras possibilidades de pesquisa no acervo SJP, nos dedicamos ao trabalho de investigação da caixa 33 A - "Estudos de SJP (Manuscritos) por temas e autores", mais especificamente as pastas 1 ("Sensibilidades") e 8 ("Grupo Sensibilidades") ${ }^{6}$, que tratam das Sensibilidades. Tais manuscritos (fichamentos, reflexões escritas, rascunhos de textos ou apresentações), são exemplos de estudos que Pesavento fazia sobre a temática, os quais, posteriormente, foram dando origem aos seus textos mais importantes sobre sensibilidades.

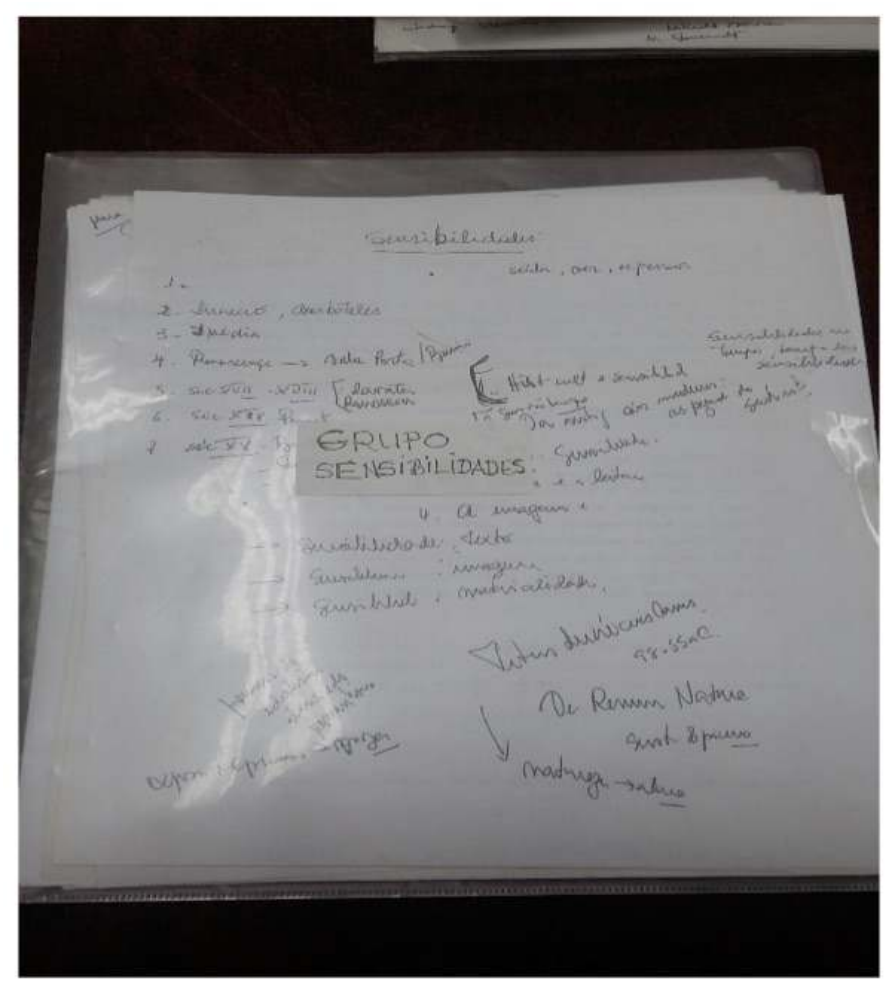

Figura 1- Capa da Pasta 8 - "Grupo Sensibilidades", organizada por Sandra Pesavento. Acervo SJP, caixa 33 [manuscritos de SJP]. Fotografia 153429, acervo pessoal de Nádia Maria Weber Santos.

34 Na pasta 8 (Figura 1), nomeada pela historiadora como "Grupo Sensibilidades" - possível referência ao grupo parisiense de colegas que discutiam a temática - ela trabalhava, encontram-se manuscritos variados, em português e em francês, sobre o tema, incluindo apontamentos e anotações sobre o que vieram a ser seus mais importantes textos na temática. Por exemplo, o texto "Sensibilidades no tempo, tempo das sensibilidades", apresentado em francês na 1ère Journée d'Histoire des Sensibilités, que aconteceu na EHESS em Paris, em março de 2004 e publicado a seguir na revista Nouveau Mondes ${ }^{7}$. As ideias deste texto são exaustivamente trabalhadas por Sandra em seus manuscritos, como nos mostram as imagens das figuras 4 e 5 (mais adiante neste texto): como capturar as sensibilidades do passado, quais são as suas traduções para o mundo? Pesavento refere suas ideias já, atualmente, conhecidas por todos, em que as sensibilidades seriam o núcleo primário de percepção e tradução do mundo e essa tradução equivale a perceber representações que traduzem significados: ações, práticas, ritos e gestos; materialidades e imagens; palavras, textos e sons (figura 4). 
35 As perguntas que ela faz, buscando um método para trabalhar tais sensibilidades são: o que são as sensibilidades? Como as capturar no passado? Quais são as suas traduções, ou dito de outra maneira, quais são os traços que deixam de si? Com isto, Pesavento começa a balizar um método, esboça seus passos de como cercar as sensibilidades passadas.

Como referido à nota 8 deste texto, os manuscritos são muitos e, ao examiná-los atentamente, observa-se que Pesavento exaustivamente está pensando as sensibilidades, em termos de epistemologia, método e de fontes para o historiador.

O contato com tais documentos, tantos os manuscritos quanto as publicações da referida autora, foi revelando possibilidades de lançar um olhar investigativo sobre o Campo das Sensibilidades sob outra nuance: enquanto método de análise histórica. Neste caminho de pesquisa, selecionamos alguns manuscritos que foram fotografados e serão aqui apresentados, cujo conteúdo evidenciam pressupostos e percursos metodológicos para o trabalho do historiador inserido neste campo. Abordaremos os seguintes aspectos: 1) Atitude hermenêutica como forma de compreensão do passado - "uma leitura sensível do tempo"; 2) A subjetividade, a experiência e as marcas de historicidade enquanto tradução e via de acesso às sensibilidades; 3) Pressupostos metodológicos para o trabalho do historiador.

Os vários manuscritos referentes às sínteses de leituras e estudos - fichamentos produzidos por Sandra Pesavento descortinam uma pesquisadora que, em aderência aos princípios da História Cultural, vai formulando um método de análise histórica de perspectiva interdisciplinar, dialogando com diferentes áreas e campos do conhecimento, a exemplo da Filosofia, Sociologia, Psicologia, Literatura, Fenomenologia e Hermenêutica etc., bem como distintos autores.

Destes entrelaces teóricos, nota-se que a relação entre a História e a Hermenêutica assume um papel de relevo em seus estudos e publicações sobre as Sensibilidades. Os dois manuscritos apresentados a seguir (Figuras 2 e 3) revelam o interesse de Pesavento em elaborar seu pensamento a partir da interlocução com culturalistas alemães como Wilhelm Dilthey e Gustav Droysen (século XIX) e o pensador e filósofo francês Paul Ricoeur (século XX), tal como se pode ver nos dois manuscritos a seguir: 


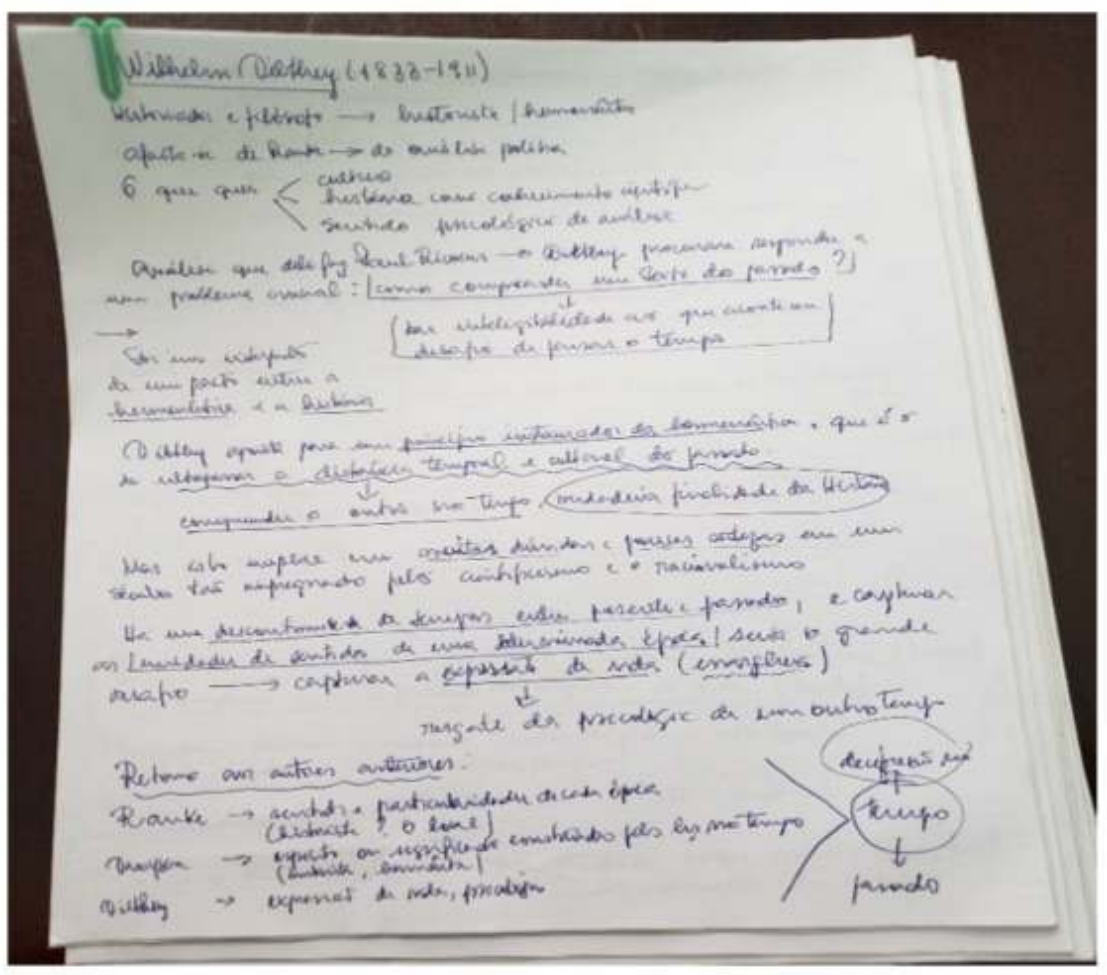

Figura 2 - Pasta 1 - "Sensibilidades", organizada por Sandra Pesavento. Acervo SJP, caixa 33 [manuscritos de SJP]. Fotografia 143640, acervo pessoal de Nádia Maria Weber Santos

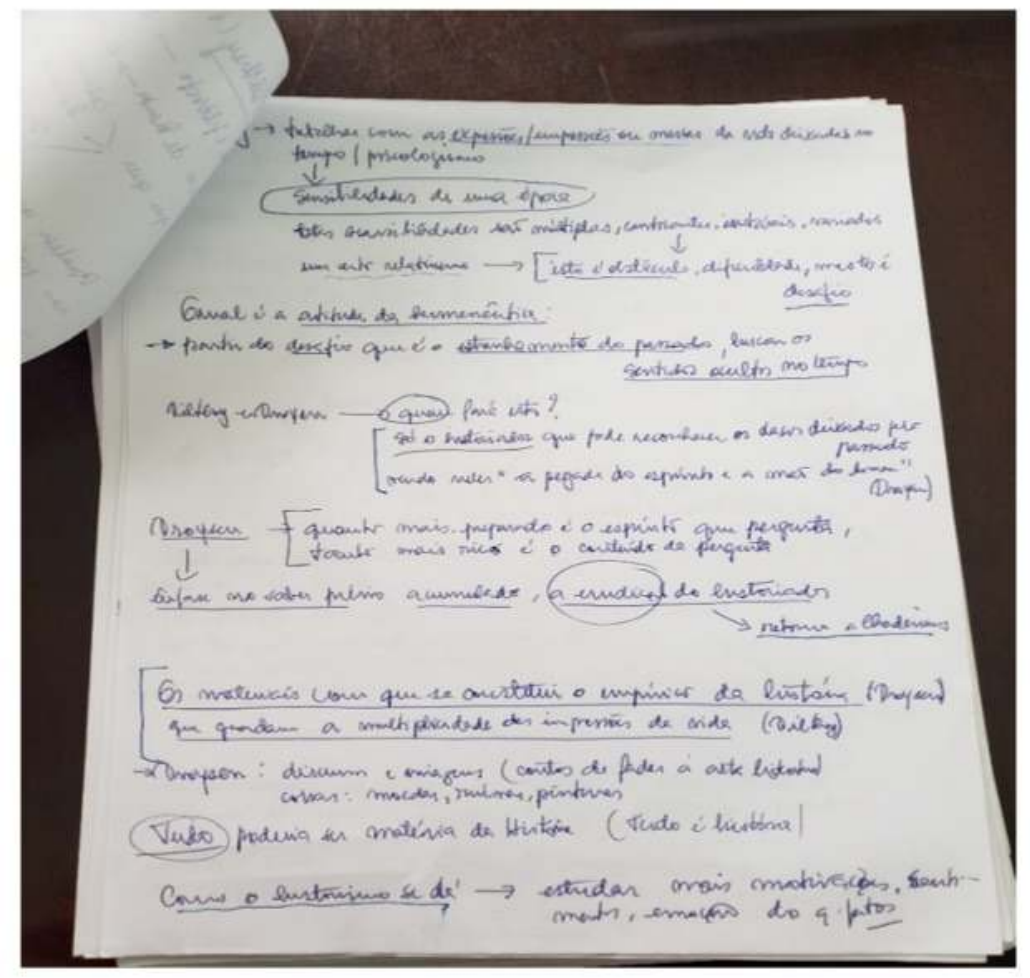

Figura 3 - Pasta 1 "Sensibilidades", organizada por Sandra Pesavento. Acervo SJP, caixa 33 [manuscritos de SJP]. Fotografia 143648, acervo pessoal de Nádia Maria Weber Santos

Nos manuscritos das figuras 2 e 3, Sandra Pesavento resgata de Wilhelm Dilthey e Paul Ricoeur o que ela chama de "a grande questão para o historiador: como compreender o 
texto do passado?" Tal pergunta encaminha à História a um pacto com a Hermenêutica, cuja finalidade é a de interpretar a experiência humana em sua dimensão temporal (PESAVENTO, 2003, 2007). Vários apontamentos presentes nesse manuscrito estão sistematizados no seguinte argumento: "A grande questão que se colocaria ao historiador seria: como compreender um texto do passado? Ao tratar a inteligibilidade daquilo que teria se passado um dia, seria preciso enfrentar o desafio de pensar a temporalidade do acontecido em termos do princípio básico da hermenêutica, que é o de ultrapassar a distância temporal e cultural do passado, compreendendo este outro no tempo, verdadeira finalidade da história" (PESAVENTO, 2007: p. 16).

Este trabalho de decifração do passado, ao modo como pensa a historiadora Pesavento, pressupõe captar na historicidade a dimensão cultural e psicológica que constitui a experiência humana, aquilo que traduz a expressão da vida... "a própria energia da vida, a enargheia, de que nos fala Cario Ginzburg. Capturar a enargheia, a força da vida, seria a meta última e refinada daquele interessado em reconfigurar o tempo do passado" (PESAVENTO, 2007: p. 13). Compreender a história, sob o viés das Sensibilidades, significa compreender não apenas um outro tempo, mas também um outro no tempo, ou seja, as formas de ver, perceber e sentir dos homens de uma outra época. Desse modo, o trabalho com as sensibilidades é uma das possibilidades de acesso e interpretação do passado (PESAVENTO, 2003).

Tal como aparece nos manuscritos aqui analisados e que reverberam nos textos publicados por Pesavento, o trabalho de compreensão e reconfiguração do passado exige do historiador "uma atitude hermenêutica - partir do desafio que é o estranhamento do passado, buscar os sentidos ocultos no tempo" (manuscrito figura 2). A articulação entre história, cultura e psicologia pode ser aqui traduzida em três princípios orientadores do trabalho do historiador: a) uma percepção inscrita sob o signo da alteridade "a história envolve sempre uma diferença no tempo, uma estrangeiridade com relação ao que se passou por fora da experiência do vivido"; b) uma compreensão da cultura - os sentidos que os homens atribuem ao mundo; c) um sentido psicológico da análise - decifrar sentidos no tempo, capturando lógicas, sentimentos, emoções e afetos (PESAVENTO, 2003, 2007). O historiador está, portanto, diante de sua tarefa primordial: realizar uma hermenêutica do passado (PESAVENTO, 2007: p. 18).

Ao buscar recriar o passado através das sensibilidades de uma outra época, o historiador lida com outras formas de apreensão da realidade que recobrem o campo do sensível, o que envolve uma "re-educação do olhar". o trabalho do historiador, guiado por uma questão de pesquisa, por lentes teóricas e metodológicas, além do referencial de contingência, configura-se também como registros sensíveis de sua interpretação do passado, uma percepção sensível e inteligível do tempo (PESAVENTO, 2003; 2007). Nessa perspectiva, Pesavento propõe uma hermenêutica das sensibilidades, tarefa do historiador. Mas como realizá-la?

Embora, atualmente, o campo das Sensibilidades inclua outras disciplinas e áreas transdisciplinares, que primam por estas discussões, como a Literatura, a Filosofia, as Artes em geral, a Psicologia, Memória Social, entre tantas outras, Pesavento se questionava e refletia sempre a partir do campo da História Cultural, que era o lugar de onde ela percebia o mundo como pesquisadora. Desta forma, é adequado perguntar: com o que lida o historiador no Campo das sensibilidades? Como traduz e acessa as sensibilidades? Como medir o imensurável? - perguntas estas que estão sempre nos 
estudos de Pesavento (exemplos nas Figuras 4 e 5, mas que aparecem em muitos outros manuscritos).

Para responder tais questões, encontram-se nas reflexões e posteriores obras, três categorias, se assim as podemos nomear, que Pesavento vislumbrou enquanto vias de acesso ou balizadores da tradução das sensibilidades: subjetividade, experiência e marcas de historicidade. Tais categorias traduzem seu método de chegar perto das sensibilidades dos homens do passado, a partir de determinadas fontes 'sensíveis', como mostram as figuras 4 e 5 a seguir.

Conforme argumenta a autora, as sensibilidades, objeto a ser capturado pelo historiador da cultura, trouxe para os domínios da História Cultural a emergência da subjetividade, que remete à presença do eu como agente e matriz de sensações e sentimentos. É através da experiência histórica pessoal que se pode capturar emoções, afetos e sentidos, de modo que essa tradução sensível da realidade seja historicizada e socializada para os homens e as condições de existência de uma determinada época (PESAVENTO, 2005; 2007).

Para Pesavento, todo indivíduo, imerso em sua subjetividade, exterioriza suas emoções e afetos, ao ser tocado por determinada experiência e, desta forma, deixa rastros de si, tangíveis, "manifestação exterior de uma experiência íntima, individual e coletiva" (manuscrito figura 4), ou seja, suas marcas de historicidade. O historiador lida, portanto, com a interpretação de uma realidade que vai desde o indivíduo à sensibilidades coletivas, reconstruindo a experiência sensível do acontecido (PESAVENTO, 2005; 2007). Para tanto, precisa se voltar a uma condição básica na tarefa do fazer história: fundamentar sua narrativa nas marcas de historicidade, recorrer a fontes e registros do passado que, organizados e interpretados, constituem-se em provas e legitimam o discurso historiográfico (PESAVENTO, 2007).

Em uma de suas primeiras publicações relevantes sobre o tema, no livro "História e História Cultural (2003), ela sistematiza o que encontramos em seus rascunhos e reflexões de arquivo: "é este mundo do sensível que incide justo sobre as formas de valorizar, classificar o mundo ou de reagir diante de determinadas situações e personagens sociais. Em suma, as sensibilidades estão presentes na formulação imaginária do mundo que os homens produzem em todos os tempos. Pensar nas sensibilidades, no caso, é não apenas mergulhar no estudo do indivíduo e da subjetividade, das trajetórias de vida, enfim. É também lidar com a vida privada e com todas as suas nuances e formas de exteriorizar - ou esconder - os sentimentos". (PESAVENTO, 2003: $p$ $.58-9)$ 


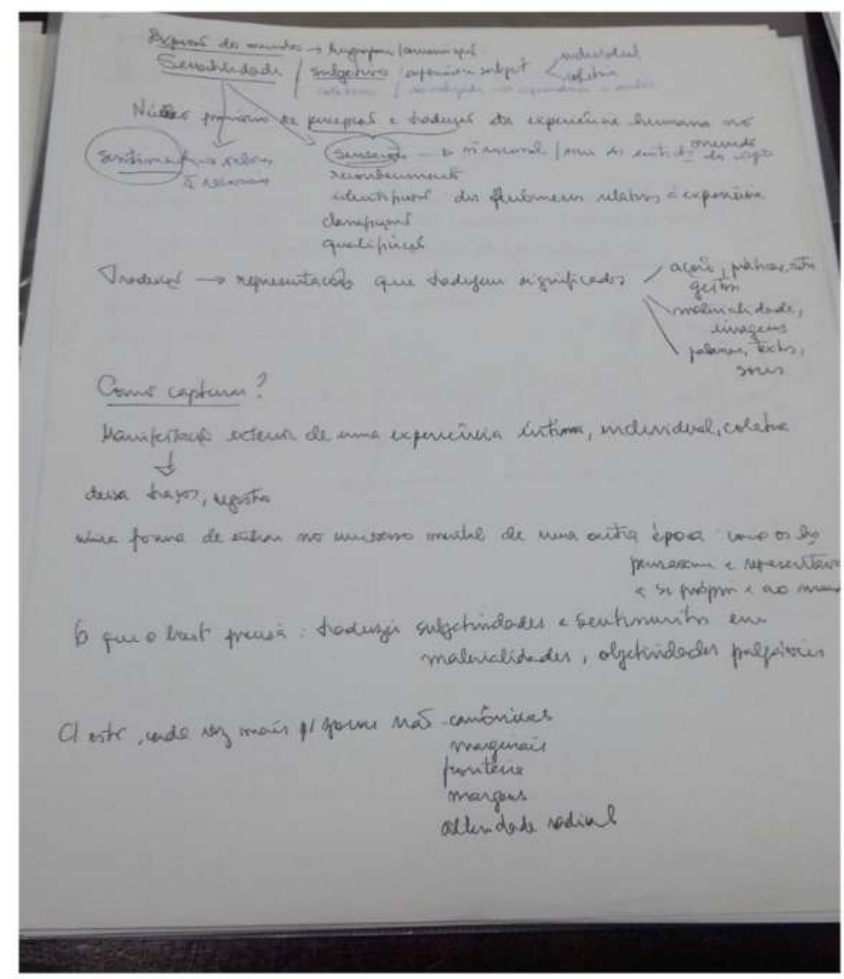

Figura 4 - Pasta 8 "Grupo Sensibilidades", organizada por Sandra Pesavento. Acervo SJP, caixa 33 A [manuscritos de SJP]. Fotografia 154207, acervo pessoal de Nádia Maria Weber Santos

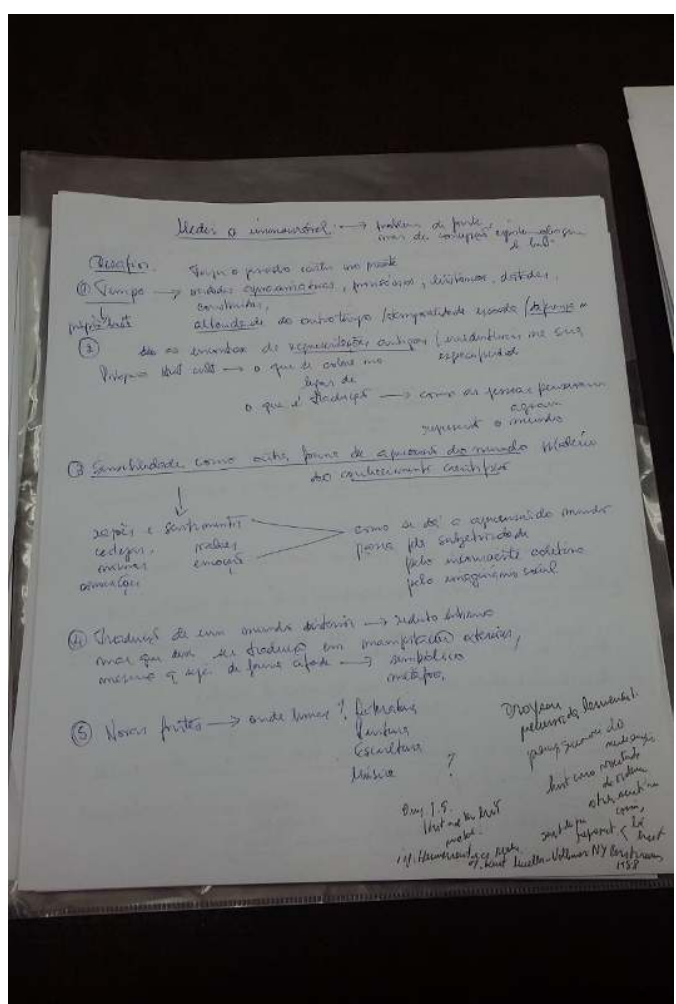

Figura 5 - Pasta 8 "Grupo Sensibilidades", organizada por Sandra Pesavento. Acervo SJP, caixa 33 A [manuscritos de SJP]. Fotografia 154840, acervo pessoal de Nádia Maria Weber Santos

A noção de "marcas de sensibilidade", como contraponto indispensável àquela de "traços" ou "marcas de historicidade", caracteriza-se como aqueles elementos que 
remetem para "fora" de um texto ou de uma narrativa, numa alusão de que a narrativa não é suficiente a ela mesma para expressar dados do passado (SANTOS, 2008). Estas marcas subjetivas (de sensibilidades) concretizam-se em fontes (por exemplo, na literatura, escultura, música, entre outras - Manuscrito Figura 5), deixando registros históricos (marcas de historicidade), "que devem ser traduções exteriores, mesmo que seja de forma cifrada - simbólico, metáfora” (Manuscrito Figura 5).

Entre tantas possibilidades de "marcas de historicidade", a literatura foi um tipo especial de fonte muito trabalhada por Pesavento, pois ela traz a subjetividade e a sensibilidade do passado, daquilo que um dia foi vivido, sentido, percebido de uma outra forma, ou da forma como podia ser naquele momento. Ciente de que este novo olhar é apenas uma versão sobre o passado, o historiador tenta apreender o registro das nuanças das sensibilidades de uma época, seus valores, conceitos, noções sobre a vida dos homens e suas práticas sociais. (SANTOS, 2008)

51 Não é possível colocar aqui, por questão de espaço, as imagens de tantos outros manuscritos em que a pesquisadora trata disto, mas na referida caixa $33 \mathrm{~A}$, que ora citamos e examinamos, há muitos estudos sobre isto. Daremos, assim, um único exemplo, referente ao seu estudo da obra de Florence Lotterie, chamada Littérature et Sensibilité (1998), onde, em sua espécie de resenha, Pesavento escreve: "sensibilidade como aventura da individualidade", "sensibilidade vem da inteligência, do pensamento, percepção e sensibilidade vem da experiência, sensação e sentimento". (Pasta 1, Caixa 33 A, itens 17 e 18 fotografados)

Para Lotterie (1998), o termo sensibilidade aparece em seu estudo como especificamente ligado à pesquisa das práticas culturais do sentimento como recurso documentar dos arquivos, mas também das artes e da literatura. Nas palavras desta autora, a sensibilidade - palavra ambígua - aparece, ainda, como uma "aventura da individualidade", que se aplica tanto aos estados afetivos, como aos "sentidos", enquanto meio de percepção. "Mas sobretudo, a etimologia mantém a flutuação entre o domínio do sensivel e o domínio do razoável (razoável enquanto razão humana)". (LOTTERIE, 1998: p.14)

53 Pesavento tem estas reflexões nas bases de suas construções deste campo, usando como método de análise histórica estas categorias levantadas aqui, pensando na literatura como uma espécie de fonte profícua de busca das subjetividades, experiências e marcas de historicidade deixadas por certos atores sociais do passado.

54 Além da literatura, como sinaliza Pesavento no manuscrito da figura 5, variadas fontes (escultura, pintura, música) - e poderíamos acrescentar aqui muitas outras - comparecem como forma de acesso e tradução das sensibilidades de uma dada época, registros de um tempo e materialidades que se dão a ler enquanto testemunhos do sensível.

Esta hermenêutica sensível implica ir além das fontes tradicionais, pois abre-se um leque de possibilidades, e, mais que isso, requer do historiador outras formas de trabalho que coadunem com este campo teórico e metodológico. Extraímos algumas proposições e caminhos metodológicos propostos por Pesavento $(2005,2007)$ que, juntamente com as questões discutidas anteriormente, elucidam as Sensibilidades enquanto método de análise histórica:

a) O historiador das sensibilidades "mais do que estudar os fatos em si, vai tentar ler nas fontes as motivações, sentimentos, emoções e lógicas de agir e pensar de uma época, pois suas perguntas e questões são outras" (PESAVENTO, 2007: p. 19); 
57 b) Nesta busca pelas "evidências do sensível" - que traduzem a complexidade da experiência humana do passado, é preciso uma reeducação do olhar, bem como uma espécie de método detetivesco "recolhendo sinais, indícios, tecendo correlações, estabelecendo nexos entre as marcas, preenchendo lacunas e ausências". Tal como argumenta a autora, uma hermenêutica do olhar se faz necessária (PESAVENTO, 2007: p. 19);

c) Do mesmo modo, "o poder interpretativo do olho deve ser estimulado para dar a ver e ler as marcas do passado". O trabalho do historiador, mediante a articulação entre o texto e o extratexto, seu saber acumulado e sua carga emotiva, consiste "em interpretar sinais, estabelecendo nexos e relações, uma rede de superposição e contraposição dos traços, em relações de analogia, contraste e combinação" (PESAVENTO, 2007: p. 20),

d) Para o historiador, a tarefa de recuperar sensibilidades não significa senti-las da mesma forma, a busca "é de tentar explicar como poderia ter sido a experiência sensível de um outro tempo pelos rastros que deixou". É a capacidade de leitura do pesquisador, apoiado nas fontes, que permite ir "além da lacuna, do vazio, do silêncio" (PESAVENTO, 2003: p. 132).

60 e) "Não há, pois, como deixar de ter em conta aquilo que é próprio da história: o fato de que as respostas construídas sobre o tempo escoado são sempre provisórias, cumulativas, parciais, datadas, prováveis e que o historiador busca tornar, sempre, o mais possível, verossímeis e convincentes. Ao estabelecer os marcos desses filtros do passado, é que a atividade do historiador se constrói como uma tarefa hermenêutica" (PESAVENTO, 2003: p. 133).

61 Ainda tendo como eco a voz de Pesavento, afirmamos, portanto, que as questões aqui apresentadas são reveladoras de que a tradução sensível do passado não se trata de um problema de fonte, antes sim de uma concepção epistemológica, outro modo de compreensão da realidade. Tal tarefa, própria do historiador, e pensada aqui aos moldes de uma hermenêutica das sensibilidades, exige um mergulho profundo na complexidade da experiência humana, uma capacidade interpretativa excepcionalmente fina, uma leitura sensível do tempo.

\section{Considerações finais}

O material que compõe o acervo Sandra Jatahy Pesavento se configura em uma possibilidade de percorrer rastros da História Cultural e das Sensibilidades, entendendo a formação deste campo do conhecimento - conceitos, pressupostos e métodos de análise e como Sandra Pesavento os incorpora, cria e recria na sua produção historiográfica.

63 A potencialidade do acervo é uma questão a ser pensada e que deve orientar para sua interpretação e para sua divulgação, no hoje e no amanhã: como já dissemos, os escritos da professora assim como as transcrições de fontes, desde sua 'fase marxista' e da Revolução Farroupilha, até suas últimas reflexões sobre urbano, sensibilidades, paisagens e imagens, estão amplamente representados na composição deste arquivo pessoal e remetem a muitas possíveis pesquisas, não somente no campo da História Cultural, mas em outros, também, como da História do Rio Grande do Sul, um viés econômico, abrindo um leque de possibilidades que permitem entrever o caráter de vitalidade que configura a História e sua produção epistemológica. 
Tem-se, assim, um campo aberto à transversalidade e à interdisciplinaridade, ao mesmo tempo que um instrumento teórico heurístico para conhecer e problematizar diferentes questões que se entrelaçam e configuram a realidade histórica. Isso revela um constante e vertiginoso movimento da produção investigativa, também congruente com a perspectiva da História Cultural e das Sensibilidades.

Pesquisar o acervo pessoal e intelectual Sandra Jatahy Pesavento é, portanto, um caminho para pensar possibilidades e desafios teóricos e metodológicos da História Cultural e das Sensibilidades, colocando em cena novas questões, temas, objetos de pesquisa e fontes, nesta roda dinâmica que é a história e o trabalho do historiador, do pesquisador. É, portanto, um caminho profícuo para investigações e descobertas, um campo dinâmico... sempre aberto a novas reflexões e planos de leitura sobre a realidade, a produção do conhecimento, o pensar e fazer História.

\section{BIBLIOGRAFIA}

HEYMANN, Luciana Quillet. De "arquivo pessoal' a "patrimônio nacional": reflexões acerca da produção de " legados". Rio de Janeiro, CPDOC, 2005.

LOTTERIE, Florence. Littérature et sensibilité. Paris, Ellipses, 1998.

PESAVENTO, S. J. Uma outra cidade: o mundo dos excluídos no final do século XIX. São Paulo,Editora Nacional, 2001.

PESAVENTO, S. J. História \& História Cultural. Belo Horizonte: Autêntica, 2003.

PESAVENTO, S. J. Sensibilidades no tempo, tempo das sensibilidades. Revista Nouveaux Mondes/ Mundos Nuevos, Paris, 2004. Disponível em https://journals.openedition.org/nuevomundo/229. Acessado em 14/10/2018.

PESAVENTO, S. J. Sensibilidades: escrita e leitura da alma. PESAVENTO, S. J.; LANGUE, F. (Orgs.). Sensibilidades na história: memórias singulares e identidades sociais. Porto Alegre, Editora da UFRGS, 2007.

PESAVENTO, S. J.; SANTOS, N. M. W.; ROSSINI, M. (Orgs). Narrativas, imagens e práticas sociais: percursos em História Cultural. Porto Alegre, Asterisco, 2008.

PESAVENTO, S. J. Os Sete Pecados da Capital. São Paulo, Hucitec, 2008.

PESAVENTO, S. J. Visões do Cárcere. Porto Alegre, Zouk, 2009.

SANTOS, Nádia Maria Weber. Histórias de vidas ausentes: a tênue fronteira entre a saúde e a doença mental. Passo Fundo, Editora da UPF, 2005. 1 ed. 191p. 2ed revista e ampliada - São Paulo, Edições Verona, 2013.

SANTOS, Nádia Maria Weber. Narrativas da Loucura e Histórias de sensibilidades. Porto Alegre, editora da Universidade, 2008.

SANTOS, N. M. W. A sensibilidade na vida e obra da historiadora Sandra Pesavento - a questão da interdisciplinaridade, postura crítica e a História Cultural. Fênix - Revista de História e Estudos Culturais (UFU. Online), v. 6, p. 1-21, 2009. Disponível em: http://www.revistafenix.pro.br/ 
PDF20/ARTIGO_1_DOSSIE_Nadia_Maria_Weber_dos_Santos_FENIX_JUL_AGO_SET_2009.pdf Acessado em 22/10/2017. Acessado em 09/11/2017.

SANTOS, Nádia Maria Weber. Quando as sensibilidades tomam posição... A obra de Sandra Jatahy Pesavento e sua importância para a historiografia brasileira. In: LEENHARDT, J. (et al.) História Cultural da cidade: homenagem à Sandra Jatahy Pesavento. Porto Alegre, Marca/Visual, PROPUR, 2015. p. 271-296.

SANTOS, N. M. W. Constituição e organização do acervo Sandra Jatahy Pesavento no IHGRGS. Anais do III Seminário Internacional de História do Tempo Presente. UDESC, outubro, 2017. Florianópolis. Disponível em: http://eventos.udesc.br/ocs/index.php/STPII/IIISIHTP/paper/ viewFile/585/472 Acessado em: 09/11/2017.

SANTOS, Nádia Maria Weber; MEIRELES, Maximiano Martins de Meireles. Rastros da História Cultural e das Sensibilidades: o acervo Sandra Jatahy Pesavento e sua produção historiográfica, Bilros, Fortaleza, v. 5, n. 10, p. 11-32, set.-dez., 2017. Seção Dossiê Temático.

VIDAL, Laurent. Acervos pessoais e memória coletiva - alguns elementos para a reflexão.

Patrimônio e Memória. UNESP - FCLAs - CEDAP, v.3, n.1, 2007.

\section{NOTAS DE FIM}

1. Para mais informações consultar o site http://www.ihgrgs.org.br .

2. O acervo está apresentado e descrito no site do IHGRGS http://www.ihgrgs.org.br/, no seguinte caminho, havendo online o inventário provisório das caixas, pastas suspensas e gavetas: http://www.ihgrgs.org.br/ - IHG digital - Arquivo online - Acervo Sandra Jatahy Pesavento 2017. 3. As obras digitalizadas da autora encontram-se no seguinte link do site do IHGRGS: http:// ihgrgs.org.br/\#SandraPesavento . Acessado em 25/09/2018.

4. Disponível em http://sandrapesavento.org/ Acessado em 25/09/2018.

5. Para uma visão completa de sua produção, ver seu Lattes, na Plataforma do CNPQ, no endereço http://lattes.cnpq.br/1760145213009265 .

6. Cada uma destas pastas 1 e 8 , pertencentes à Caixa 33 A do Acervo SJP, contém um número grande de documentos (Pasta 1 "Sensibilidades" - 104 itens, Pasta 8 "Grupo Sensibilidades"- 111 itens), entre escritos à mão e digitados em computador, organizados pela própria Pesavento. Nesta seção serão incluídas imagens de alguns destes documentos, apenas, para fins de ilustração, e de alguns outros para mostrar ao leitor, também, alguns de seus conteúdos, que serão discutidos no texto, a fim de que ele descortine, por si mesmo, a importância de tais documentos. Devido ao escopo e extensão do artigo não será trabalhado um número grande de documentos das referidas pastas.

7. Sensibilidades no tempo, tempo das sensibilidades. Revista Nouveaux Mondes/Mundos Nuevos, Paris, 2004. Disponível em https://journals.openedition.org/nuevomundo/229. Acessado em 14/10/2018.

\section{RESUMOS}

O texto discute o lugar, a importância e os conteúdos específicos da temática das Sensibilidades na obra da historiadora Sandra Jatahy Pesavento, a partir dos documentos de seu arquivo pessoal, depositado no Instituto Histórico e Geográfico do Rio Grande do Sul desde final de 2014. O material completo do Acervo Sandra Jatahy Pesavento tem em torno de 114 metros lineares e, dentre os diversos focos de conteúdos, que perpassam as várias fases da historiadora e 
pesquisadora da UFRGS, atemo-nos aos manuscritos sobre Sensibilidades, uma vez que Pesavento foi uma das pioneiras na historiografia brasileira neste campo teórico. Discute-se algumas possibilidades de investigação no acervo, tendo no horizonte as Sensibilidades enquanto campo teórico e método de análise histórica.

Le texte traite de la place, de l'importance et du contenu spécifique du thème "Sensibilités" dans les travaux de l'historienne Sandra Jatahy Pesavento, à partir de ses documents personnels, déposés à l'Institut d'histoire et de géographie du Rio Grande do Sul depuis fin 2014. Le fonds compte environ 114 mètres linéaires de documents. Parmi les différents domaines abordés au cours des différentes phases de son travail à l'UFRGS, nous nous en tiendrons aux manuscrits portant sur le thème «Sensibilités». L'article discute quelques pistes de recherche possibles dans le fonds, gardant l'idée de «Sensibilité» comme horizon théorique et méthodologique d'analyse historique, ce qui fit la singularité de la grande et regrettée historienne Sandra Jatahy Pesavento, pionnière brésilienne dans ce domaine théorique.

\section{ÍNDICE}

Palavras-chave: Arquivo pessoal. Sensibilidades. Teoria e Metodologia. Sandra Pesavento. História Cultural.

Mots-clés: Archives, sensibilités. théorie et méthodologie.

\section{AUTORES}

\section{NÁDIA MARIA WEBER SANTOS}

Dra. em História. Professora do PPG em Performances Culturais da UFG (Universidade Federal de Goiás). Autora de vários livros e artigos na área da História Cultural, com ênfase em História da Loucura e da Psiquiatria, Memória Social, Sensibilidades, Arquivos pessoais e Performances Culturais. Destacam-se as obras individuais: Histórias de vidas ausentes: a tênue fronteira entre a saúde e a doença mental ( $2^{\mathrm{a}}$ edição ampliada e revista, SP: Edições Verona, 2013); Histórias de sensibilidades e narrativas da Loucura (Porto Alegre, Ed. da Universidade/ UFRGS, 2008)

\section{MAXIMIANO MARTINS DE MEIRELES}

UNEB. Dr. em Educação

maxymuus@hotmail.com 